\title{
WEBER Y BENJAMIN: RELIGIÓN Y CAPITALISMO
}

\author{
[ WEBER AND BENJAMIN: CAPITALISM AND RELIGION ]
}

\author{
Sergio Lomeli * \\ Universidad Nacional Autónoma de México, México
}

\begin{abstract}
RESUMÉn: El presente ensayo analiza el desarrollo del argumento de Max Weber sobre la relación entre ética puritana y capitalismo frente al desarrollo del argumento de Walter Benjamin en torno a la descripción del capitalismo como religión. $\mathrm{Si}$ bien se ha presentado el texto de Benjamin como una radicalización de la tesis weberiana, el presente artículo propone que esa descripción puede ser equívoca, y parece insuficiente para describir la relación entre estos dos autores: Benjamin no radicaliza, en el sentido de continuar de forma extrema, la tesis de Weber; sino que construye una tesis esencialmente distinta. Mientras Weber plantea una relación de 'afinidades electivas' entre la ética puritana y el capitalismo, Benjamin plantea una relación de identidad entre ambas. A partir de esta distinción se sostiene que de estas aproximaciones se desprenden consecuencias políticas mutuamente excluyentes.
\end{abstract}

Palabras-clave: Weber, Benjamin; capitalismo; religión; ética protestante
ABSTRACT: This paper examines Max Weber's argument on the relationship between Puritan ethics and capitalism, in contrast to Walter Benjamin's description of capitalism as religion. Benjamin's text has been presented as a radicalization of Max Weber's thesis, yet this paper posits that this description is equivocal and insufficient to depict the relationship between both authors: Benjamin does not radicalize, in the sense of continuing in an extreme form, Weber's thesis, but rather construes an essentially different thesis. Whilst Weber portrays a relationship of "elective affinities" between Puritan ethics and capitalism, Benjamin establishes a relationship of identity amongst them.

This distinction allows to understand that mutually exclusive political consequences are obtained from these approximations.

KEYwORDs: Weber; Benjamin; capitalism; religion; Protestant ethics

La miseria religiosa es, al mismo tiempo, la expresión de la miseria real y la protesta contra la miseria real. La religión es el suspiro de la criatura atormentada, el alma de un mundo desalmado, y también es el espiritu de situaciones carentes de espíritu. La religión es el opio del pueblo.

(MARX, 2005, p. 50)

$\mathrm{E}$ n el presente texto voy a presentar la aproximación de Max Weber y Walter Benjamin a la relación que se puede encontrar entre religión y capitalismo. La tesis principal de este trabajo pretende demostrar que hay una diferencia cualitativa fundamental entre la aproximación de Weber, y la aproximación de Benjamin y que ello implica posturas políticas incompatibles. Es sabido que el extracto de Benjamin titulado "El

* Profesor Titular de asignatura en la Facultad de Filosofia y Letras de la Universidad Nacional Autónomade México.m@ilto: sergio.lomeli@uaem.mx 
capitalismo como religión" se pone en relación explícita con los trabajos de Weber; sin embargo, los análisis que se ofrecen sobre este extracto en la literatura contemporánea no se detienen en señalar que el texto de Benjamin no es sólo una radicalización de la tesis de Weber, sino más precisamente la construcción de una tesis esencialmente distinta. Mientras Weber expone la relación entre ética puritana y capitalismo a partir de la figura de 'afinidades electivas', Benjamin construye una tesis sobre la superposición de lo religioso y lo económico en el capitalismo. Para Benjamin no es un problema de afinidades electivas, es una cuestión de identidad: el capitalismo subsume, en el sentido de que incorpora y supera, a la religión. Como se puede ver, son dos tesis cualitativamente distintas que tienen implicaciones políticas igualmente distintas.

Habría que decir que los textos que van a ser analizados adolecen de una profunda asimetría. Mientras que los dos ensayos que conforman La ética protestante y el espíritu del capitalismo son textos ampliamente desarrollados y fundamentados por Weber, el extracto póstumo "El capitalismo como religión" de Benjamin es apenas el esbozo, cuya extensión es cercana a las tres cuartillas, de algo que pudo llegar a ser un texto más desarrollado. Este trabajo presenta una asimetría semejante en la medida en que mientras la sección dedicada al argumento de Weber es analítica y expositiva, la sección dedicada al texto de Benjamin resulta interpretativa y propositiva.

\section{WEBER: UNA CUESTIÓN DE AFINIDADES ELECTIVAS.}

Para una sociedad de productores de mercancías, cuya relación social general de producción consiste en comportarse frente a sus productos como frente a mercancias, o sea valores, y en relacionar entre si sus trabajos privados, bajo esta forma de cosas, como trabajo humano indiferenciado, la forma de religión más adecuada es el cristianismo, con su culto del hombre abstracto, y sobre todo en su desenvolvimiento burgués, en el protestantismo, deísmo, etc.

(MARX, 2001, p. 96)

En La ética protestante y el espíritu del capitalismo, Max Weber construye una tesis que pone en relación elementos religiosos con el modo de producción capitalista. Valdría la pena, comenzar por hacer un deslinde. La primera recepción en América, que se deriva de la traducción de Talcott Parsons al inglés de La ética protestante, sostiene que ésta es una suerte de respuesta idealista al materialismo histórico, donde se demuestra cómo la religión determina los procesos materiales económicos. Una lectura atenta al texto y a la obra weberiana muestra cómo esto no es el caso. En Economía y sociedad, Weber (2005, p. 310, pp. 495 s.) data el origen del capitalismo hacia finales de la Edad Media, mucho antes de la reforma protestante. La tesis debería ser más bien leída como una de 'afinidades electivas': ahí donde la ética protestante se arraigó socialmente, el capitalismo se desarrolló más rápidamente (SCHLUCHTER, 1985, pp. 142-143; VILLEGAS, 2004, pp. 10-15). Weber toma el término 'afinidad electiva' de una novela de Goethe, que lleva ese título, quien a su vez había recuperado un concepto que estaba en boga en la química del siglo XVIII. El término se usaba para intentar explicar la misteriosa interacción entre ciertos minerales que implicaba la agudización de ciertas características (ESTANY; IZQUIERDO, 1990, p. 355).

Para Weber hay dos elementos relevantes que ayudan a interpretar y entender la ética protestante como una ética de la ascesis intramundana: el primero es la concepción de vocación o profesión que introduce Lutero en su traducción al alemán de la Biblia; el segundo es la idea de predestinación que surge con Calvino y es retomada por algunas sectas protestantes.

En su estudio, Weber (2004, p. 129 y ss) encuentra que en la palabra alemana Beruf (profesión), así como en la palabra inglesa calling (llamado), que son palabras equivalentes, se encuentra un dejo de religiosidad: ambas traducen la idea del cumplimiento de una 
misión divina. Más precisamente, el término luterano se refiere a la idea de trabajo como vocación, no un trabajo específico, sino a cualquier trabajo que se pueda realizar lícitamente en el mundo. Según Weber este uso de la palabra alemana Beruf nació de una traducción más libre que literal de la Biblia hecha por Lutero. Weber llega a afirmar que no sólo la palabra sino también la idea es producto de la Reforma luterana (Vid Ibíd. pp. 130-134). Algunos especialistas consideran problemática la traducción de este término porque nace en la lengua alemana y se utiliza mayoritariamente en lenguas influidas por la Reforma, de manera que, sostienen, no hay un término suficientemente preciso para dicho concepto en las lenguas de las naciones que no fueron fuertemente influenciadas por las ideas reformadas. Este sería el caso del español, donde 'vocación' tiene dicho matiz religioso, pero, en su origen, sólo sería válido utilizarlo en sentido eclesiástico, mientras que 'profesión' tendría únicamente el sentido de cometido o misión de manera secundaria (RUANO DE LA FUENTE, 2001).

Weber sostiene que la traducción del término responde a los intereses de Lutero de reaccionar en contra de la moral católica. Ésta hacía una distinción de las normas evangélicas entre praecepta y concilia, donde los primeros (preceptos o mandamientos de la Iglesia) rigen a todos los miembros bautizados de la Iglesia a partir de los siete años y son cinco: santificación del domingo, asistencia a misa, abstinencia y ayuno en los días señalados por la iglesia, confesión anual y comunión pascual; mientras que los segundos (consejos evangélicos o votos) sólo rigen a las órdenes monásticas y son tres: pobreza, castidad y obediencia (Ibidem). Para Lutero, esta distinción representaba una huida egoísta del mundo por parte de la moral católica y su vida ascética monacal. Por ello, Weber (2004, p. 138) sostiene que: "Según Lutero, es evidente que la conducción de vida monástica [...] es el producto de un desamor egoísta, que trata de sustraerse del cumplimiento de los deberes que precisa cumplir en el mundo. Surge así como contraste la idea a la vez profana y religiosa del trabajo profesional como manifestación palpable del amor al prójimo [...]". Es de este enfrentamiento a la moral católica egoísta que surge la idea de 'profesión' como cumplimiento en el mundo de la misión impuesta por Dios. Weber (Ibídem) afirma que para Lutero "[...] el cumplimiento en el mundo de los propios deberes es el único medio de agradar a Dios, que eso y sólo eso es lo que Dios quiere, y que, por lo tanto, toda profesión lícita posee ante Dios absolutamente el mismo valor."

Éste es el primer paso que da la ética protestante para acercarse al espíritu del capitalismo. Weber (2004, pp. 92-94), ejemplifica a lo que se refiere por este término con una cita a un texto de Benjamin Franklin:

Piensa que el tiempo es dinero. El que puede gana [sic] diariamente diez chelines con su trabajo y dedica a pasear la mitad del día, o a holgazanear en su cuarto, aún cuando sólo dedique seis peniques para sus diversiones no ha de contar esto sólo, sino que en realidad ha gastado, o más bien derrochado, cinco chelines más. Piensa que el crédito es dinero [...] Piensa que el dinero es fértil y reproductivo [...] Piensa que, según el refrán, un buen pagador es dueño de la bolsa de cualquiera [...] Además, has de mostrar siempre que te acuerdas de tus deudas, has de procurar parecer siempre como un hombre cuidadoso y honrado, con lo que tu crédito ira en aumento. Guárdate de considerar como tuyo todo cuanto posees y de vivir de acuerdo con esa idea [...]" Y más adelante dice: "Es Benjamín quien nos predica en estos principios [...] No hay duda de que en este documento habla, con su peculiar estilo, 'el espíritu del capitalismo' [...].

La ética protestante hace de las actividades que se realizan en este mundo, lo más alto y virtuoso a lo que un creyente puede aspirar. Al mismo tiempo se suprimen las actividades de la ascesis monacal precisamente porque para su cumplimiento se requiere de un alejamiento del mundo (GIDDENS, 1991; KALBERG, 1990).

[...] lo absolutamente nuevo era considerar que el más noble contenido de la 
propia conducta moral consistía justamente en sentir como un deber el cumplimiento de la tarea profesional en el mundo. Tal era la consecuencia inevitable del sentido, por así decirlo, sagrado del trabajo, y lo que engendró el concepto ético-religioso de profesión: concepto que traduce el dogma común a todas las confesiones protestantes [...] y que como único modo de vida grato a Dios reconoce no sólo la superioridad de la eticidad intramundana por medio de la ascesis monástica, sino precisamente el cumplimiento en el mundo de los deberes intramundanos que a cada cual impone la posición que ocupa en la vida, y que por lo mismo se convierte para él en 'profesión'. (WEBER, 2004, p. 136)

La gran aportación de Lutero es reformar una ética que tenía la pretensión de trascender el mundo, en una ética intramundana, donde lo que se considera valioso ya no es el alejamiento del mundo para buscar la virtud, sino precisamente el ser virtuoso dentro del mundo. En palabras de Weber: "Lo propio y específico de la Reforma, en contraste con la concepción católica, es haber acentuado el matiz ético y aumentado la primacía religiosa concedida al trabajo en el mundo, racionalizado en 'profesión'." (Ibid., p. 141)

Si bien Lutero da un primer paso para acercar una ética religiosa al espíritu del capitalismo, su visión del mundo le impide llevar la concepción de 'profesión' hasta sus últimas consecuencias. Según Weber, Lutero tenía un límite tradicionalista que le impide racionalizar desde el punto de vista formal el actuar en el mundo, por lo tanto en lugar de adaptar y dirigir el qué se hace en el mundo para conseguir los fines religiosos buscados (honrar a Dios o cualesquiera que fueran), se acepta la condición dada como divina e incuestionable (RUANO DE LA FUENTE, 2001; HAMILTON, 2000; GIDDENS, 1991). Weber (2004, pp. 145-146) explica el punto de vista de Lutero de la siguiente forma: "Profesión es aquello que el hombre ha de aceptar porque la Providencia se lo envía, algo ante lo que tiene que 'allanarse'; y esta idea determina la consideración del trabajo profesional como misión [...] impuesta por Dios al hombre [...]”.

Esta postura tradicionalista fue trascendida por Calvino y las sectas protestantes influidas por sus ideas. El estudio de Weber sobre el ascetismo intramundano no sólo contempla la aportación de Calvino y el calvinismo a la ética protestante, sino que estudia a todas las sectas puritanas de los siglos XVI-XVIII. Weber utiliza el término 'puritano' de manera amplia, y por él entiende precisamente todas las sectas ascéticas protestantes. Su estudio incluye pues, al calvinismo, pietismo, metodismo y las sectas que surgieron del movimiento baptista (Vid Ibíd., pp. 155-156). Sin embargo, a pesar de las diferentes aportaciones doctrinarias de estos grupos, la decisiva para constituir una ética del ascetismo intramundano proviene del calvinismo. Gil Villegas (2004, p. 26) resume el argumento de la siguiente manera: "una cierta interpretación del sentido de la predestinación calvinista y de la división del mundo entre elegidos y condenados, condujo a un ascetismo intramundano de dominio del mundo, mismo que suscitó una ética acorde con una mentalidad económica identificada con el término [...] de un 'espíritu capitalista'." Y Weber (2004, p. 159) dice: "El calvinismo es la idea religiosa a que primeramente hemos de referirnos, por haber sido la determinante de cuantas luchas se llevaron a cabo en torno a la religión y la cultura en los países más desarrollados desde el punto de vista del capitalismo (Países Bajos, Inglaterra y Francia)." Siendo este el caso, esta exposición sólo cubrirá la aportación calvinista, dejando a un lado el desarrollo de las aportaciones del pietismo, metodismo y baptismo.

Para describir el dogma de la predestinación, Weber recurre a la Westminster Confession de 1646. En ella se encuentra el siguiente pasaje:

Para revelar su majestad, Dios por su decreto ha destinado [...] a unos hombres a la vida eterna y sentenciado [...] a otros a la eterna muerte [...] Aquellos hombres que están destinados a la vida han sido elegidos en Cristo para la gloria eterna por Dios, antes de la creación, por su destino eterno e inmutable, su decreto secreto y el arbitrio de su voluntad, y ello por libre amor y gracia; no porque la previsión de la fe o de las buenas obras o de la perseverancia en una de las dos u otra 
circunstancia semejante de las criaturas la hubieran inclinado, como condición o como causa, sino que todo es premio de su gracia soberana. (WEBER, 2004, p. 162.)

El dogma de la predestinación supone que es absurdo pensar que las obras humanas tienen algún efecto sobre las disposiciones divinas, de manera que para los calvinistas creer que portarse bien, o arrepentirse de las malas obras, u obtener el perdón por parte del sacerdote es absolutamente irracional. Como Dios es omnipotente y omnisapiente, las disposiciones divinas son completamente inconcebibles e ininteligibles por las mentes mortales, además, las acciones humanas están a la misma distancia de alterar el orden divino de las cosas como los está la mente de los mortales de comprender o conocer las disposiciones divinas. Weber (Ibíd., p. 165) explica que: "Lo único que sabemos es que una parte de los hombres se salvará y la otra se condenará. Suponer que el mérito o la culpa humanas colaboran en este destino significaría tanto como pensar que los decretos eternos absolutamente libres de Dios podrían ser modificados por obra del hombre: lo que es absurdo."

Concebir así la predestinación tiene varias consecuencias. La salvación, o bien, el estado de gracia, no sólo no está bajo control de las acciones del hombre sino que además éste no puede recurrir a nadie, ni a nada para poder disminuir la angustia que le causa el no saber si está en gracia o condenado al fuego eterno.

[Al puritano] Nadie podía ayudarle; no el predicador, porque sólo el elegido era capaz de comprender espiritualmente la palabra de Dios; no los sacramentos, porque estos son, es verdad, medios prescritos por Dios para aumento de su gloria (por lo que han de practicarse absolutamente), pero no son medios para alcanzar la gracia [...] Tampoco la Iglesia [...] Por último, tampoco Dios podía prestar aquella ayuda, pues el mismo Cristo sólo murió por los elegidos [...] Este radical abandono (no llevado hasta sus últimas consecuencias por el luteranismo) de la posibilidad de una salvación eclesiástico-sacramental, era el factor decisivo frente al catolicismo. Con él llega a su culminación el proceso de 'desencantamiento' del mundo que [...] rechazó como superstición y ultraje todos los medios mágicos para buscar la salvación. (Ibíd., pp. 166-167.)

De esta cita interesa el punto que tiene que ver con la generación de un sentimiento nunca antes conocido de angustia y soledad interior: el creyente no tenía ningún refugio, ningún lugar del cual asirse, se sentía condenado a recorrer en soledad el camino hacia su destino. Ese sentimiento de soledad y retracción hacia el interior del creyente, generó un sentimiento de aversión y desprecio hacia 'los elementos sensibles y sentimentales' de la cultura y religiosidad así como de la civilización material (Vid Ibíd., p. 168). Esto, como se verá más adelante, afectó el modo de conducción de vida de algunos protestantes y los llevó a una vida ascética que implicaba no sólo la entrega metódica y disciplinada a la 'profesión', sino también el ahorro, pues los bienes materiales eran inútiles para la obtención de la salvación.

Durante la vida de Calvino, el dogma se sostuvo radicalmente, la única vía para saber si uno estaba en estado de gracia era la autoconfirmación a través de la fe. El dogma se transformó con los sucesores de Calvino, de manera que se empezaron a aceptar ciertos signos mundanos para conocer el estado de gracia. Sobre esto, Hamilton (2000, p. 156) afirma que:

Calvino restringió el conocimiento del juicio sobre el individuo a Dios. Sólo Él podía saber quién estaba salvado y quién condenado, y la criatura estaba condenada a permanecer en ignorancia. Esto cambió con los sucesores de Calvino [...] más tarde en el siglo XVI y durante el inicio del siglo XVII la idea de que la elección era reconocible fue creciendo y la doctrina de la predestinación implicó que el individuo mismo podía de hecho tener cierta certeza de su destino. Las 
buenas obras, recompensadas exitosamente, se convirtieron en una señal de la aprobación divina.

Una vez que se da este paso en el dogma de la predestinación, se puede entender cómo la dedicación a la 'profesión' adquiere un matiz distinto al que le había dado Lutero. Si con el alemán, la 'profesión' ya entregaba al hombre a la actividad intramundana, con el calvinismo y la doctrina de predestinación, la dedicación metódica a la 'profesión' y el éxito en ella se convierte en el único medio para aliviar la angustia provocada por la ignorancia sobre el propio estado de gracia. Así, se racionaliza formalmente la conducción de vida: para tener certeza de mi estado de gracia, lo que necesito hacer no es arrepentirme, ir a misa ni cualquier otra forma sacramental de salvación, sino conducir mi vida metódicamente para honrar a Dios por medio de una dedicación absoluta a mi 'profesión' (WEBER, 2004, pp. 179-180; KALBERG, 1990, p. 77 y ss).

De esta manera, para el calvinista, no hay buena acción que mágicamente le salve ni le pueda aliviar de su angustia, de hecho, toda forma de sacramento mágico-religioso para la salvación se ve como pecaminosa. El calvinista, a diferencia tanto del católico como del luterano, crea su propia salvación, o más precisamente como dice Weber, crea la seguridad de encontrarse en el estado de gracia a través de su ascetismo intramundano ${ }^{1}$.

En resumen, hay dos cuestiones que nos resultan centrales para entender la concepción del mundo a partir del pensamiento reformado. Por un lado está la aportación del término Beruf (profesión) por parte de Lutero, que tiene como consecuencia reformar la acción ética y volverla intramundana proceso que llega a su culminación con Calvino. Por otro lado, está la doctrina de la predestinación, y su reformulación por parte de los sucesores de Calvino. A través de ella se afirma que puede haber señales para conocer el estado de gracia, por ejemplo el éxito en el desempeño de la propia profesión. Así, si se quiere tener control sobre el estado de gracia se necesita racionalizar la conducción de vida por medio de apegarla estrictamente a la consecución de la permanencia en el estado de gracia.

En la reedición de sus ensayos, Weber desarrolla el proceso de racionalización formal que implica el giro de la ética protestante a través de la inserción de la idea del desencantamiento del mundo ${ }^{2}$. Este término no sólo implica el proceso progresivo en que se elimina todo resquicio de magia como método para alcanzar la salvación, sino precisamente describe el proceso por el cual algunos protestantes fueron transformando su forma de conducción de su vida, de manera metódica y ajustándola a un fin. Suele llamarse a esto, desde otras aproximaciones, un proceso de secularización. Una vez que se asume que no hay acción posible que mágicamente pueda ofrecer una salvación, lo más racional desde el punto de vista del calvinista es vivir como un santo, no sólo un día, ni por un acto de arrepentimiento aislado, sino vivir sistemáticamente como santo. Precisamente por ello el proceso de ascetización intramundana de los protestantes, es un proceso de racionalización formal: se trata del arreglo u orientación progresiva y sistemática de las formas de vida a la consecución de fines:

El 'desencantamiento' del mundo, la eliminación de la magia como medio de salvación no fue realizada en la piedad católica con la misma consecuencia que en la religiosidad puritana [...] Para el católico [...] el sacerdote era el mago que [...] garantizaba la emancipación de la terrible angustia, vivir en la cual era para el calvinista destino inexorable, del que nada ni nadie puede redimirle; para él no había esos consuelos [...] ni siquiera podía esperar, como el católico y aun el luterano, reparar por medio de las buenas obras las horas de debilidad [...] El Dios del calvinista no exigía de sus fieles la realización de tales o cuales 'buenas obras', sino una santidad en el obrar elevada a sistema [...] De este modo perdió la conducta moral del hombre medio su carácter anárquico e insistemático [sic], sustituido ahora por una planificación y metodización total del modo de conducción de vida. (WEBER, 2004, pp. 188-189) 
A pesar de que en ningún sentido era la intención de los puritanos el promover una ética afín al espíritu del capitalismo, ese fue el resultado. En la última sección de La ética protestante, Weber se dedica a explorar esta relación. En primer lugar, hay que entender que el ascetismo intramundano no perseguía la ganancia ni aprobaba, en principio, la aspiración a la riqueza por la riqueza misma; sin embargo, el hecho de respaldar la dedicación metódica a la profesión favoreció, indudablemente, la creación de lo que Weber llama un 'racionalismo económico'. Lo reprobable de la riqueza era la tentación del descanso y la vida ociosa, ese era el verdadero pecado. Para el puritano, el problema de la riqueza es que el poseedor de ella se podía ver tentado a abandonar su actividad profesional para perder el tiempo ociosamente mientras debería ocuparlo para glorificar a Dios. Como se mostró más arriba, el trabajo empezó a constituir el primer mandamiento. Weber afirma que si bien todavía no se sostiene 'el tiempo es dinero' como va a hacer Franklin, al menos el principio ya está asentado en el orden religioso. El tiempo es valiosísimo porque sirve para honrar a Dios y cada segundo que se pierde en ociosidades es un segundo que se le roba a la gloria de Dios.

Partiendo de estos principios el puritano se fue conformando con un modo de vida afín al espíritu del capitalismo, según Weber, mucho más parecido a la moderación burguesa que a los lujos y extremos de la aristocracia y los nuevos ricos. Así el puritano no teme pecar cuando se dedica a ganar y acumular riqueza. El puritano ahorra por principio, no gasta un solo centavo en algo que no glorifique a Dios. La consecuencia de racionalizar el trabajo, condenar al consumo y retirar todas las trabas éticas al enriquecimiento es la formación de capitales que se tienen que emplear productivamente para glorificar a Dios ${ }^{3}$, lo que "fue favorable sobre todo para la formación de la conducción de vida burguesa y racional (desde el punto de vista económico) [...]” (WEBER, 2004, pp. 276-277).

Si bien, para Weber, la relación entre ascetismo intramundano y espíritu capitalista estaba ya en los principios de la ética protestante, su influencia en el ámbito económico no llegó a desarrollarse con toda su fuerza sino hasta tiempo después. Tardó para que los motivos religiosos se fueran olvidando y la metódica práctica profesional perdiera toda necesidad de justificación ultraterrena. Para Weber, lo que empezó como virtud se convirtió en costumbre, y terminó por diluirse en una fría práctica utilitaria. Weber cierra sus ensayos con la metáfora de la jaula de hierro.

El puritano quiso ser un hombre profesional, nosotros tenemos que serlo también; pues desde el momento en que el ascetismo abandonó las celdas monásticas para instalarse en la vida profesional y dominar la eticidad intramundana, contribuyó en lo que pudo a construir el grandioso cosmos de orden económico moderno que, vinculado a las condiciones técnicas y económicas [...] determina hoy con fuerza irresistible el estilo vital de cuantos individuos nacen en él [...] y de seguro lo seguirá determinando durante muchísimo tiempo más (Ibid., p. 286).

Es verdaderamente notable que Weber observa que a inicios del siglo xx ya no había opción sobre esto. Si bien los puritanos se habían planteado la transformación de su conducción de vida para poder de esa manera honrar a Dios, consiguieron afectar la organización social moderna. Hoy no es posible elegir vivir de manera irracional (desde el punto de vista formal económico), estamos condenados a seguir el modo de vida burgués, que por lo demás, según Weber, ya no tiene nada que ver con honrar a Dios. Weber (Ibidem) dice: "La jaula ha quedado vacía de espíritu, quien sabe si definitivamente. En todo caso el capitalismo victorioso no necesita ya de este apoyo religioso, puesto que descansa en fundamentos mecánicos." La jaula metaforiza la forma ascética de conducción de vida que era un medio para alcanzar el fin de glorificar a Dios y tener certeza del estado de gracia; esta jaula se queda vacía de espíritu, es decir que, según Weber, pierde toda fundamentación y sentido ético-religioso que era precisamente lo que le hacía ser medio, para ahora funcionar mecánicamente como fin en sí misma. 


\section{BENJAMIN: UNA CUESTIÓN DE IDENTIDAD.}

Feuerbach disuelve la esencia religiosa en la esencia humana.

Pero la esencia humana no es un abstractum inherente al individuo singular. En su realidad, es el conjunto de las relaciones sociales [...]

Feuerbach no ve, por tanto, que el propio 'ánimo religioso'es un producto social, y que el individuo abstracto que él analiza pertenece

a una forma determinada de sociedad.

(MARX, 2011,pp. 116-177)

Walter Benjamin es conocido por sus diversos y agudos pasajes en los que critica al capitalismo a partir de temas e imágenes religiosas. Tal vez los más conocidos son los que se encuentran en sus Tesis sobre el concepto de historia (BENJAMIN, 2008): ahí encontramos enanos teológicos, débiles fuerzas mesiánicas y ángeles nuevos criticando y construyendo visiones de historia. En este ensayo me centraré en un texto de 1921, casi veinte años previo a las Tesis, también breve, y tal vez un poco menos conocido que se llama El capitalismo como religión. Mi intensión es acercar este texto temprano de Benjamin, a esas Tesis sobre el concepto de historia que se escriben tantos años después y en un contexto radicalmente distinto. La propuesta es que, las Tesis pueden echar luz sobre este texto, que de otra forma resulta en gran medida críptico. La relación entre $\mathrm{El}$ capitalismo como religión y las Tesis parece estar justificada en le medida en que el propio Benjamin, al escribir la carta a su amiga Gretel Adorno en donde le habla de la Tesis sobre el concepto de historia le confiesa que son ideas que había tenido en resguardo, incluso de sí mismo, durante 20 años (ECHEVERRÍA, 2005).

Hace algún tiempo, Michael Löwy (2006) nos llamó la atención hacia ese texto, y sostuvo que debía ser leído como una radicalización de la tesis de Max Weber. Ahí mismo, Löwy señala que es evidente, a todas luces, que el texto se inspira en la obra de Weber, pero que reemplaza su "modo de andar 'axiológicamente neutral' por una fulminante denuncia anticapitalista [[...] surtout, il remplace sa dermarché 'axiologiquement neutre' (Wertfrei) par un fulminant réquisitoire anticapitaliste]." Además, agrega que el argumento benjamineano no está tan lejos de la conclusión weberiana, pero que agrega la novedosa idea de la naturaleza propiamente religiosa del capitalismo.

Sería imposible no concordar con Löwy sobre el hecho de que el texto está en diálogo con La ética protestante, pues hacia el inicio del fragmento, Benjamin (2016, p. 187) hace referencia a la tesis weberiana explícitamente: "La demostración de esta estructura religiosa del capitalismo — no sólo, como opina Weber, como una formación condicionada por lo religioso, sino como un fenómeno esencialmente religioso- derivaría aún hoy en una polémica universal desmedida." Es evidente, a lo largo del texto, que Benjamin asume y utiliza el estudio de Weber para hacer sus propias reflexiones. Sin embargo, no me parece del todo acertada la tesis de que es una radicalización anticapitalista de la misma ni que la conclusión esté cerca de la conclusión weberiana. En notar la diferencia entre estas tesis se juega el sentido de términos tales como 'radicalizar' y 'anticapitalista'. Incluso, en su forma más amplia está en juego el problema de qué es hacer crítica; donde están implicadas las consecuencias políticas de una y otra tesis.

Sobre el problema referente a la crítica, quisiera decir que la tesis de Weber se ajusta a su definición del quehacer sociológico como una ciencia interpretativa y explicativa que no tiene por finalidad, en ningún sentido, ser deontológica ni normativa (WEBER, 2005). Weber es particularmente cuidadoso en este aspecto y por ello se ha descrito su producción teórica como neutral. Sin embargo, la afirmación de Löwy podría ser leída de forma que implicara sutilmente, y tal vez sin proponérselo, que es necesario ser 'axiológicamente parcial' para ser crítico del capitalismo. Desde esta perspectiva, el texto de Benjamin resultaría crítico, en oposición al de Weber, en la medida de su parcialidad axiológica. 
Frente a una lectura así, habría que rescatar una concepción de 'crítica' que no estuviese condicionada por la parcialidad o imparcialidad de sus valores. Más aún, habría que recuperar el quehacer crítico cuyo proceder apuesta por la deconstrucción de los valores imperantes para su comprensión teórica y no por la proposición de valores distintos. En este segundo sentido, me parece que los textos de Weber y Benjamin son semejantes.

Desde este punto de vista, la tesis de Weber sería crítica en la medida en la que pone lado a lado una ética religiosa y el modo de actuar en el capitalismo y desvela con ello algo que estaba oculto para el ojo común. Si bien Weber no compartió las tesis revolucionarias de sus contemporáneos, sería impreciso no ver en su aproximación teórica una crítica del capitalismo. El sentido de la descripción 'anticapitalista' presenta entonces una ambigüedad que habría que atender. ¿Qué significa ser 'anticapitalista' si no quiere decir simplemente ser crítico del capitalismo?

Si bien es cierto que el texto de Weber no es ni pretende ser revolucionario, y por ello no podría ser descrito como 'anticapitalista' desde esa acepción del término; también es igualmente cierto que el texto de Benjamin tampoco es 'revolucionario' ni programático de forma explícita. Por tanto, la descripción tampoco sería válida en ese caso. Se ha afirmado que El capitalismo como religión no es de la época marxista de Benjamin dado que fue escrito a finales de 1921 (ENNIS; FOFFANI, 2016) y que en todo caso denota mayor influjo de la obra Llamada al socialismo (Aufruf zum Sozialismus) del pensador radical Gustav Landauer (LÖWY, 2006; ENNIS; FOFFANI, 2016). Aun así, no se encuentra en el texto ninguna evidencia explícita que indique una política revolucionaria. Desde mi perspectiva, la diferencia entre ambas posturas críticas al capitalismo que se encuentran en los textos de Weber y Benjamin, radica en las implicaciones políticas que se desprenden de cada una. Mientras que la postura de Weber resulta trágica en sus implicaciones políticas; la de Benjamin no. Para Weber, la jaula de hierro es inevitable, es un mal necesario e irrevocable. Para Benjamin, el hecho de que el capitalismo sea ahora religión no es un problema cerrado. En este otro sentido, me parece, sus anticapitalismos son distintos: el texto de Benjamin no es revolucionario, pero su concepción está abierta, como se verá más adelante, a la posibilidad de reflexionar sobre el tema revolucionario.

También habría que decir que el término 'radicalización', como está en Löwy, parece prometer una agudización o bien un ir hasta el extremo de algo; incluso si lo se entiende en su uso técnico, como un ir hasta la raíz del problema. En ambos casos, el término 'radicalización' presenta una relación de continuidad con el objeto del cual se radicaliza: o se va hasta el extremo, o se va hasta la raíz. En el caso que interesa, el uso de ese término apunta a presentar la relación entre las tesis de Weber y Benjamin como una relación de continuidad, como si no hubiera interrupción o ruptura, como si lo que encontráramos fuera un incremento cuantitativo al máximo de las propiedades específicas de una misma tesis. Sin embargo, me parece que dicha descripción no retrata con justicia la relación entre estos textos. Habría que ver que entre la tesis de Weber y la de Benjamin hay un salto cualitativo. Como aquellos saltos a los que apela Hegel en la Ciencia de la lógica (2011, p. 411-412), cuando describe las transformaciones en la naturaleza:

No hay ningún salto en la naturaleza [, se dice]; y, como ya se ha recordado, la representación habitual opina, cuando debe concebir un surgir o un perecer, que lo ha concebido cuando se lo representa como un paulatino brotar o desaparecer. Pero ya se ha demostrado que los cambios en la esfera del ser, en general, no son solamente el transitar de un cuanto a otro cuanto, sino la transición de lo cualitativo a lo cuantitativo y viceversa: un venir a ser otro que es un corte abrupto de lo paulatino y algo cualitativamente-otro respecto al estar precedente.

En este caso, la imagen de Hegel sirve, por analogía, para representar los saltos y disrupciones en el mundo de la teoría. El salto cualitativo que propongo está denotado en los subtítulos de este texto: Para Weber la relación entre el protestantismo puritano y el 
espíritu del capitalismo es una de afinidades electivas, donde las propiedades de uno exaltan las propiedades del otro; sin embargo, se refiere a dos cosas claramente independientes y distintas. Para Benjamin la relación es de 'identidad': el capitalismo es una religión, no son dos cosas que van bien juntas, es una sola cosa la que es objeto de estudio. Ambas tesis son específicamente distintas y tienen consecuencias políticas muy distintas.

La referencia que hace Benjamin al texto de Weber, y que fue citada más arriba, establece explícitamente una negación, que marca una diferencia. Benjamin no sólo cita a Weber para establecer una posible filiación entre su texto y el de Weber, sino más bien para marcar una ruptura: "[...] no sólo, como opina Weber, como una formación condicionada por lo religioso, sino como un fenómeno esencialmente religioso [...]" (BENJAMIN, Loc. cit.) La cita no sólo denota conocimiento sobre el texto de Weber, sino, sobre todo, rechazo frente a la tesis fundamental ahí sostenida. La enunciación de la tesis de Benjamin es que el capitalismo tiene rasgos estructurales de religión, ya no es un 'modo de producción' cualquiera, es un 'modo de producción' que se comporta religiosamente: "En el capitalismo puede reconocerse una religión. Es decir: el capitalismo sirve esencialmente a la satisfacción de los mismos cuidados, tormentos y desasosiegos a los que antaño solían dar una respuesta las llamadas religiones." (Ibidem)

Para Benjamin, llega un momento en la historia del cristianismo en que éste es subsumido por el capitalismo, que hasta entonces se había desarrollado como parásito suyo, habría ahí un proceso de incorporación y superación: "El capitalismo [...] se ha desarrollado en Occidente como parásito del Cristianismo, de tal forma, que al fin y al cabo su historia es en lo esencial la historia de su parásito, el capitalismo." (Ibid., p. 188). Es decir, Benjamin retrata la relación de forma en la que, al inicio, el capitalismo es meramente un parásito del cristianismo; sin embargo, más adelante el parásito termina por consumir al huésped y sustituirlo completamente: "El Cristianismo del tiempo de la Reforma no propició el ascenso del capitalismo, sino que se transformó en el capitalismo." (Ibid., p. 189). Como se ve en éstas últimas aseveraciones, Benjamin denuncia una hibridación entre el capitalismo y el cristianismo de la Reforma protestante, en donde lo que era parásito se convierte en el único organismo.

Para echar luz sobre este tema, quiero referir un trabajo de Agamben que aporta ciertas herramientas conceptuales particularmente pertinentes. En "Elogio de la profanación", Agamben (2009) nota una cuestión interesante de la religión cristiana que sirve para promover el argumento que me interesa. En ella hay una porosidad o confusión entre los planos de lo sagrado y lo profano. En la construcción de su argumento, Agamben rastrea el problema hasta la ambigüedad etimológica del vocablo latino profanare, que parece designar a la vez el acto de sustracción de algo divino y su devolución al mundo humano, y el movimiento inverso de 'sacrificar', aunque este uso haya sido mucho más raro. Si bien sobre este tema ya había reflexionado famosamente en otro lugar (AGAMBEN, 1998), aquí, Agamben menciona cómo en el cristianismo se sobreponen los planos de lo sagrado y lo profano como momento constitutivo de esa forma específica de religiosidad: En la encarnación, la divinidad se vuelve mundana; en la transustanciación, durante la misa, Dios mismo es sacrificado. Concluye de ello que en el cristianismo ya había una estructura que iba a habilitar la incorporación de lo religioso en el capitalismo, pues los planos sacros y profanos habían colapsado en el mismo locus teológico: el cristo.

Resulta de esto que, en el cristianismo, con el ingreso de Dios como víctima en el sacrificio y con la fuerte presencia de tendencias mesiánicas que ponían en crisis la distinción entre lo sacro y lo profano, la máquina religiosa parece alcanzar un punto límite o una zona de indecibilidad, en la cual la esfera divina está siempre en acto de colapsar en la humana y el hombre traspasa ya siempre lo divino (AGAMBEN, 2009, pp. 104-105).

A partir de este análisis, Agamben dota de sentido la afirmación por medio de la cual 
Benjamin desmarca su tesis de la de Weber: "Según Benjamin, el capitalismo no representa sólo, como en Weber, una secularización de la fe protestante, sino que es él mismo un fenómeno religioso, que se desarrolla en modo parasitario a partir del cristianismo." (Ibid., p. 105). Para abrevar a esta distinción, habría que notar que Agamben distingue muy nítidamente entre secularización y profanación. Mientras secularizar implica conservar la estructura de una relación de poder al tiempo que se traslada el lugar de su ejercicio, profanar quiere decir sustraer algo de la esfera exclusiva de la divinidad y regresarla al dominio público de lo humano:

Es preciso distinguir, en este sentido, entre secularización y profanación. La secularización es una forma de remoción que deja intactas las fuerzas, limitándose a desplazarlas de un lugar a otro. Así, la secularización política de conceptos teológicos (la trascendencia de Dios como paradigma del poder soberano) no hace otra cosa que trasladar la monarquía celeste en monarquía terrenal, pero deja intacto el poder. La profanación implica, en cambio, una neutralización de aquello que profana. Una vez profanado, lo que era indisponible y separado pierde su aura y es restituido al uso. Ambas son operaciones políticas: pero la primera tiene que ver con el ejercicio del poder, garantizándolo mediante la referencia a un modelo sagrado; la segunda, desactiva los dispositivos del poder y restituye al uso común los espacios que el poder había confiscado. (Ibid., p. 102)

Esta distinción resulta particularmente pertinente para reforzar el argumento aquí expuesto. En la tesis de Weber se puede observar un proceso de secularización, profundamente desarrollado bajo la noción de desencantamiento de mundo; mientras que en la exposición de Benjamin, se puede observar un proceso de profanación. La relación descrita como de 'afinidades electivas', lo que hace es trasladar la estructura de racionalidad, y en este sentido de fuerza, desde lo religioso hasta lo económico conservando, sin embargo, la misma estructura. En cambio, la relación de identidad, sostenida por Benjamin, desactiva, o resignifica, los dispositivos de poder entregándolos a la cotidianidad de la vida concreta capitalista: a la circulación, distribución, consumo y producción de mercancías.

Por otra parte, el proceso de profanación específico de esta forma de religiosidad está revestido, para Agamben, de un carácter contradictorio: la profanación capitalista es al mismo tiempo un acto de consagración. Como se mostró más arriba, Agamben sostiene que ello ya estaba implicado en la estructura cristiana de la religión: "En su forma extrema, la religión capitalista realiza la pura forma de la separación, sin que haya nada que separar. Una profanación absoluta y sin residuos coincide ahora con una consagración igualmente vacua e integral" (Ibid., p. 107). La idea de una 'pura forma de separación' cuando no hay nada que separar, parece contradictoria; sin embargo, encuentra un sentido posible en el proceso de incorporación y superación que efectúa el capitalismo sobre el cristianismo. Si profanar es restituir al plano de lo mundano algo que se encontraba escindido y sólo accesible a los dioses; y sacralizar quiere decir separar algo de entre lo mundano para que sólo sea accesible a los dioses, entonces lo que se separa o escinde y lo que se devuelve o mundaniza sucede sobre el mismo objeto en el mismo espacio. En el capitalismo sucede que el valor, que es originalmente algo mundano, trabajo humano, se escinde de sus formas concretas para convertirse en capital, valor que se valoriza a sí mismo: el nuevo demiurgo de la realidad. Sin embargo, esa escisión no implica que el capital suceda en un otro lugar, o en otra corporeidad que no sea mundana: el demiurgo de lo real, el nuevo dios, es mundano, unas veces mercancía, otras veces forma autónoma de valor (dinero), otras veces fuerza de trabajo viva, o fuerza de trabajo muerta (MARX, 2001). Podemos usar esta aproximación para reflexionar sobre cómo en el modo de producción capitalista se desencadena un complejo proceso de 'separar y reincorporar', de resignificar las relaciones, las acciones y los objetos en un mismo sitio: el mundo capitalista. Lo sacro del capitalismo, su magia 
engendradora y reproductora de valor, sucede de forma profana en la cotidianidad de la acción humana. Ya no hay un otro lugar para el capitalismo, todo lo escindido permanece en el mismo lugar. El acto de profanación opera como seppuku en el capitalismo: al mismo tiempo que se produce un acto de sublimación, se produce un cadáver. El trabajo vivo, produce trabajo muerto; y a la inversa, el valor que se valoriza, produce valores de uso.

Una vez establecida la tesis de identidad, Benjamin se dedica a esbozar cuatro rasgos fundamentales que permiten ver al capitalismo como religión: 1) es una religión de culto sin dogma; 2) es una religión cuyo culto es ininterrumpido; 3 ) el culto religioso capitalista es culpabilizador y no expiatorio; y, 4) el dios de esta religión permanece oculto.

Habría que detenernos a analizar, interpretar y apropiarnos, una por una, de estas características con el fin de poner de relieve las potencialidades críticas del esbozo realizado por Benjamin. El primer rasgo que Benjamin señala es que el capitalismo es una religión puramente de culto, 'la más cúltica de todas las religiones'. Esto quiere decir que no cuenta con una teología dogmática. El capitalismo como fenómeno religioso se tendría que entender como una religión exclusivamente de comportamiento: "En él [el capitalismo], todo tiene significado sólo de manera inmediata con relación al culto; no conoce ningún dogma especial, ninguna teología.” (BENJAMIN, 2016, p. 187).

Parece que la característica de la religión capitalista de ser "mero culto, sin dogma", apunta a que no hay un sistema de creencias, o conjunto fundamental de éstas, que sostenga la religión capitalista. En todo caso, habría que entender que no necesita haber uno, sin importar los intentos conscientes, en mayor o menor grado, por establecer o explicar dicho dogma. El capitalismo es una religión que funciona y se actualiza por el puro culto, es decir, por la manifestación externa de sus preceptos. En las religiones no dogmáticas, esto se cumple a partir de la práctica de la ley. Es una religión de pura práctica, que tendría por implicación el apego metódico y sistemático a la ley. La ley general que rige el modo de producción capitalista es la de la autovalorización del valor, es decir, que la forma específica que asume el valor en las relaciones de producción capitalistas, debido a sus propias dinámicas, tiene por finalidad el incrementar su magnitud. Habría que subrayar nuevamente la diferencia implicada aquí entre las tesis de Weber y Benjamin. Para el segundo, no se trata de cómo la práctica religiosa puritana modifica la acción humana lo cual trae por consecuencia un fortalecimiento del capitalismo; sino que lo religioso es ahora la valorización del valor. Durante el proceso de subordinación del cristianismo reformado al capitalismo, la acción social es disciplinada para cumplir con la ley capitalista. La práctica social o culto, como manifestación externa del precepto máximo del modo de producción capitalista, actualiza el proceso de autovalorización del valor.

El segundo rasgo que menciona Benjamin es que, en el capitalismo, el culto tiene una duración permanente. Es un culto que se realiza todo el tiempo, ininterrumpidamente. No sucede como en otras religiones en las que el culto tiene tiempos y espacios sagrados determinados para llevarse a cabo: "El capitalismo es la celebración de un culto sans [t]rêve et sans merci. No hay ningún "día de semana" [,] ningún día que no sea festivo en el pavoroso sentido del despliegue de toda la pompa sagrada [,] de la más extrema tensión de los fieles." (Ibidem). La aproximación de Agamben sobre la superposición de planos sagrados y profanos es particularmente esclarecedora en este aspecto. El culto no tiene un espacio y tiempo escindido del tiempo y espacio profano; a la vez, los tiempos y espacios profanos son ya, inmediatamente, sagrados en otro sentido, en ese locus contradictorio es donde sucede la valorización del valor: Wallstreet es una de los nuevos Vaticano y las fábricas, los bancos, los malles, los hospitales, universidades, corporaciones y demás centros productivos, consuntivos y circulatorios son sus nuevas parroquias.

El análisis de Weber sobre la ascesis intramundana de la ética protestante apunta en una dirección similar: el culto sucede ahora dentro del mundo; sin embargo, no como profanación, sino específicamente como secularización. En cambio, de la aproximación de Benjamin, habría que observar que dicha característica denota que la ejecución cultual de la 
ley capitalista implica que los individuos se acomodan, de manera permanente, a la forma en que el capitalismo ha reordenado el ser social. Lo cual sugiere que cada acción que se realiza en la práctica cotidiana capitalista lo que hace es ratificar el capitalismo: Los individuos hacen lo que el culto espera de ellos. En el despertarse a una hora para ir a trabajar, en el consumo de mercancías que reproducen la vida, en el esfuerzo que se invierte en el trabajo, sea este del carácter que sea, sin importar si la naturaleza del mismo es manual o intelectual; en la producción, reproducción o conservación de relaciones sociales, laborales, políticas o afectivas. El capitalismo tiende a homogenizarlo todo, a subsumirlo todo, a incorporarlo todo; en una palabra, a profanarlo todo. Marx y Engels (1955, p. 22) habían señalado, agudamente, algo semejante en su famoso Manifiesto:

Dondequiera que ha conquistado el poder, la burguesía ha destruido las relaciones feudales, patriarcales, idílicas [...] las ha desgarrado sin piedad para no dejar subsistir otro vínculo entre los hombres que el frío interés, el cruel 'pago al contado'. Ha ahogado el sagrado éxtasis del fervor religioso, el entusiasmo caballeresco y el sentimentalismo del pequeño burgués en las aguas heladas del cálculo egoísta. Ha hecho de la dignidad personal un simple valor de cambio [...] La burguesía ha desgarrado el velo de emocionante sentimentalismo que encubría las relaciones familiares, $\mathrm{y}$ las ha reducido a simples relaciones de dinero.

Lo denotado por la segunda característica enunciada por Benjamin, es la tendencia que tiene el modo de producción capitalista a saturar extensiva e intensivamente el universo de acción social. En el sentido extensivo, el capitalismo recorre y empuja sus fronteras, permanentemente, para que ya no haya un afuera de su imperio. En el sentido intensivo, el capitalismo cada vez satura más nichos que eran internos a sus fronteras pero no se realizaban bajo su lógica. Ejemplo de ello es la incorporación nuevos valores de uso para ser mercantilizados, como lo serían los códigos genéticos de semillas o la minería de metales que antes no tenían un uso industrial.

El tercer rasgo enlistado por Benjamin es que el culto capitalista es culpabilizador, no expiatorio. Con esta característica, Benjamin quiere denotar una especificidad muy notable del capitalismo: el culto capitalista no pretende liberar de culpa, sino más bien culpabilizar más profundamente a quien lo practica.

El capitalismo es, presumiblemente, el primer caso de un culto que no expía la culpa, sino que la engendra. Aquí, este sistema religioso se arroja a un movimiento monstruoso. Una monstruosa conciencia de culpa que no sabe cómo expiarse apela al culto no para expiarla, sino para hacerla universal, inculcarle la conciencia, y finalmente sobre todo incluir al Dios mismo en esa culpa [,] para finalmente interesarlo a él mismo en la expiación. Esta no debe esperarse, pues, en el culto, ni tampoco en la Reforma de esta religión, que debería poder aferrarse a algo seguro en sí misma, ni en la renuncia a ella. En el ser de este movimiento religioso, que es el capitalismo [,] reside la perseverancia hasta el final [,] hasta la completa inculpación de Dios, el estado de desesperación mundial en el que se deposita justamente la esperanza. (BENJAMIN, 2016, pp. 187-188).

Este rasgo se presenta de forma particularmente oscura y hace referencia, tal vez, a una hibridación de la doctrina de la predestinación calvinista con el proceso de acumulación capitalista. Entre los elementos explícitos que se presentan y ayudan a fundamentar esta lectura está la mención de 'una conciencia de culpa que no sabe cómo expiarse'. En la doctrina de la predestinación, como sostuvo Weber, el creyente no tiene forma de saber si está en gracia o condenado al fuego eterno. Además, por el proceso de racionalización formal implicado en ello, el puritano sabe que su acción no puede alterar el orden divino de las cosas. Más adelante Benjamin afirma que 'finalmente' se incluye al Dios mismo en esa culpa. A partir de una lectura atenta del texto de Weber, se podría sostener que se incluye a Dios en el proceso cuando los sucesores de Calvino matizan la doctrina de la 
predestinación: En la medida en la que el culto no libera de culpa, Dios tiene que intervenir y enviar señales de gracias. Sin embargo, esas señales son específicamente afines al capitalismo. Al practicante le empieza a ir bien en la profesión que ejerce, es decir, empieza a acumular dinero. La desesperación y angustia que sufre el creyente, por su desconocimiento sobre su estado de gracia, se torna en principio teológico del capitalismo: el vacío existencial arroja al practicante al culto capitalista. La desesperación produce y reproduce cada vez más la relación capitalista. Por ello Benjamin (2016) sostiene que: "La expansión de la desesperación al rango de condición religiosa del mundo, de la cual debe esperarse la curación. La trascendencia de Dios ha caído. Pero no está muerto, está incluido en el destino humano." (p. 188).

Además, la característica parece señalar un proceso acumulativo, dado que el culto no 'expía la culpa sino que la engendra', quien realiza el culto se ve compelido a realizarlo de nuevo. Esto tiene que ver con el hecho de que el practicante no sabe que el culto es culpabilizador y deposita ahí su esperanza. El proceso podría ser descrito como uno de acumulación de culpa: el culto no sólo no exime de culpa, sino que culpabiliza cada vez más. Aquí la valorización del valor y la culpabilización del culpable se funden en un mismo plano. Como explica Marx, así como el capital no sólo produce plusvalor, sino también reproduce la relación capitalista misma; así también la reproducción ampliada del capital, no sólo produce plusvalor ampliado, sino reproduce de forma ampliada la relación capitalista misma (MARX, 2001, p. 761). Como si el entramado social que actualiza el culto capitalista, por el mismo hecho de hacerlo, estuviera más comprometido con su repetición. Cada realización del culto implica más, y compromete más a sus santos, aquellos fieles practicantes que no se desvían nunca del culto. Al actuar en el mundo capitalista los individuos se santifican cada vez más. En la permanente profanación capitalista se puede observar, simultáneamente una permanente sacralización: todos somos santos en el capitalismo.

A lo largo de la exposición y desarrollo de esta característica, Benjamin no presenta, como se argumentó más arriba, una propuesta revolucionaria o nítidamente política. En todo caso parece ensayarse una suerte de nihilismo, por ejemplo, cuando observa: "Allí reside lo históricamente inaudito del capitalismo: en que la religión ya no es la reforma del ser, sino su destrucción." (BENJAMIN, 2016, p. 188). Sin embargo, de forma subyacente, parece latir la idea de ruptura con el culto culpabilizador que hace santos de los practicantes. En la crítica y denuncia que se lee en El capitalismo como religión, el incumplimiento de esta característica se presenta como tarea política del presente. Es cierto que esta tarea no está enunciada explícitamente, pero habita el texto de manera sintomática ${ }^{4}$. El tema, sin embargo, resuena en otros lugares de la obra benjaminiana. Así, por ejemplo, en la Tesis VIII de Sobre el concepto de historia: "Entonces ya tendremos a la vista como nuestra tarea la instauración del estado real de excepción" (BENJAMIN, 2008, p. 309). Ahí, Benjamin se refería, de forma explícita, al nazismo y a la necesidad de promover un verdadero estado de excepción y no uno que, desde el punto de vista de los oprimidos, es en verdad la regla de la opresión. Sin embargo, la idea se presenta de forma sugerente y relevante para reflexionar sobre el capitalismo en general, no sólo en la versión fascista del mismo. No sería descabellado decir que las nociones de irrupción, de verdadera excepcionalidad, de hacer saltar el continuum de la historia, y de dar un 'manotazo hacia el freno de emergencia' están presentes, no sólo en las Tesis sobre la historia, sino de forma transversal en el pensamiento crítico de Benjamin. Resulta un gesto significativo el hecho de que esta idea se encuentre también en Agamben, quien cierra su "Elogio de la profanación" con la afirmación "La profanación de lo improfanable es la tarea política de la generación que viene.” (AGAMBEN, 2009, p. 119).

La propuesta de que El capitalismo como religión contiene de forma sintomática la tarea política de la interrupción o ruptura del culto, se puede ver también en la forma en que Benjamin critica la teoría de Marx. En una oración casi telegráfica, Benjamin presenta la 
teoría de Marx en la versión que la Segunda Internacional tenía de ella: como una teoría de evolucionismo económico, paulatino y sin saltos ni rupturas desde el capitalismo hasta el socialismo: "Y de manera similar Marx: el capitalismo sin conversión deviene, con el interés y los intereses acumulados, que como tales son una función de la culpa (obsérvese la demoníaca ambigüedad de este concepto), socialismo." La oración, sin la compleja cláusula subordinada, diría: 'el capitalismo sin conversión deviene socialismo'. No vale la pena en este momento deslindar la teoría de Marx de la versión de ella que hicieron popular los teóricos de la $2^{\mathrm{a}}$ Internacional. Para el argumento que aquí quiero proponer es suficiente la constatación de que Benjamin piensa que la teoría de Marx sostiene la continuidad evolutiva entre capitalismo y socialismo y lo critica por ello. Lo que se lee sintomáticamente, es que desde el punto de vista de Benjamin no hay continuidad: La otra sociedad, la emancipada, no puede ser cómplice del modo de producción capitalista. Ahí, como antes, resuena el tema del freno de emergencia: "Marx dice que las revoluciones son la locomotora de la historia mundial. Pero tal vez se trata de algo por completo diferente. Tal vez las revoluciones son el manotazo hacia el freno de emergencia que da el género humano que viaja en ese tren." (BENJAMIN, 2005, p. 37)

El cuarto rasgo que menciona Benjamin implica la invisibilidad del Dios capitalista y se relaciona con el problema de lo reprimido en su versión freudiana:

Su cuarto rasgo es que su Dios debe ser mantenido oculto, sólo el cenit de su
inculpación podrá ser invocado. El culto es celebrado ante una deidad no
madurada, cada representación de ella, cada pensamiento que se le dedica,
vulnera el secreto de su maduración. La teoría freudiana pertenece también al
dominio sacerdotal de este culto. Lo reprimido, la representación pecaminosa, es
-por una analogía más profunda y aún por iluminar- el capital, que grava
intereses al infierno del inconsciente. (BENJAMIN, 2016, p. 188)

Benjamin es consciente de la complejidad del pasaje. Benjamin afirma que lo reprimido es el capital, aunque anuncie que dicha analogía aún está por ser iluminada. ¿Qué puede querer decir que lo reprimido es el capital? Para responder es necesario andar con precisión sobre la teoría de la represión. Si bien podemos encontrar elementos dispersos desde Estudios sobre la histeria, en El yo y el ello, Freud ofrece una versión sucinta de la teoría de la represión. Afirma que para el psicoanálisis la división de lo psíquico entre consciente e inconsciente es constitutiva. Asimismo, explica cómo lo inconsciente a su vez contiene elementos que son latentes y susceptibles de consciencia y otros elementos que no lo son. Freud argumenta que hay ciertos procesos anímicos o representaciones muy intensas que pueden tener un impacto significativo para la vida anímica pero que por una cierta fuerza psíquica no devienen consciente. A esa fuerza psíquica que mantiene fuera de la consciencia a ciertos procesos anímicos o representaciones es a lo que Freud (1979, pp. 1516) llama represión: "[...] tales representaciones no pueden ser conscientes porque cierta fuerza se resiste a ello, que si así no fuese podrían devenir conscientes [...] Llamamos represión (esfuerzo de desalojo) al estado en que ellas se encontraban antes de que se hicieran conscientes [...]". Freud además afirma que, a través de ciertos medios de la técnica psicoanalítica, es posible contrarrestar esa fuerza represiva para traer al consciente las representaciones en cuestión.

Benjamin utiliza la noción de represión, para atender lo oculto del dios capitalista. Además de incluir a Freud, como había hecho con Nietzsche y Marx, entre los sacerdotes del culto (BENJAMIN, 2016, p. 188; AGAMBEN, 2009, p. 106) dice que el dios capitalista permanece oculto y 'sólo el cénit de su inculpación podrá ser invocado'. Lo que quiere decir que no se mostrará el dios mismo, sino el momento más meridiano de su inculpación, lo cual equivale a decir que sólo se mostrará en sus formas más evidentes y superficiales. En cambio, lo que permanece oculto es el dios, lo propiamente reprimido, y como Benjamin afirma, eso es el capital: "Lo reprimido, la representación pecaminosa, es [...] el 
capital." (BENJAMIN, Loc. cit.)

Se puede dar sentido a esta característica desde el análisis realizado por Marx a lo largo de El Capital. La afirmación puede parecer anacrónica en la medida en la que se argumente que Benjamin no había trabajado El Capital de Marx en 1921. Solo habría que observar que el esfuerzo de este texto no es genealógico sino interpretativo. No es mi intensión sostener que Benjamin estaba pensando en la obra de Marx cuando escribe su texto, sino ofrecer una perspectiva interpretativa que ponga de relieve sus potencialidades críticas.

En El Capital, Marx explica cómo y por qué la mercancía es fetichizada y lo que podemos llamar el proceso de enajenación de la sociedad capitalista. En cuanto al fetichismo se refiere, Marx explica cómo algo propio de la estructura mercantil tiene por efecto el ocultamiento del carácter social del producto y del fundamento de su valor. Algo permanece escondido y oculta su forma de ser. Construye un rostro falso, engañoso. Detrás del rostro fetichizado de la mercancía, lo que se esconde es la relación social que implica el proceso de producción e intercambio: "Lo misterioso de la forma mercantil consiste sencillamente, pues, en que la misma refleja ante los hombres el carácter social de su propio trabajo como caracteres objetivos inherentes a los productos del trabajo [...]" (MARX, 2001, pp. 87). Lo que Marx llama el carácter fetichista de la mercancía es meramente un síntoma de un tema mucho más complejo que podemos rastrear a lo largo de El Capital: el tema de la enajenación dentro del modo de producción capitalista. Si bien es un lugar común decir que Marx sustituyó el concepto de 'enajenación' que usó en su obra de juventud, por el concepto de fetichismo al escribir El Capital, dicha aseveración es imprecisa. El problema del fetichismo denota, por decirlo brevemente, la atribución de facultades subjetivas a los objetos mercantiles, y al mismo tiempo, el proceso inverso, el de atribuir características objetivas a los sujetos de las relaciones sociales: el fetichismo es un proceso de cosificación. Así lo explicó Lukács (1969, pp. 90-112) en Historia y consciencia de clase. Sin embargo, cuando Marx despliega su análisis de la fórmula de circulación mercantil capitalista $\left(\mathrm{D}-\mathrm{M}-\mathrm{D}^{+}\right)$en oposición a la ecuación de circulación mercantil simple, $\left(\mathrm{M}_{[1]}-\mathrm{D}-\mathrm{M}_{[2]}\right)$, el tema de la enajenación se torna central. Lo que denota la fórmula capitalista es la subsunción de la vida humana y la forma natural al proceso de valorización de valor, aquello que se llama con propiedad capital: una nueva subjetividad que ahora toma decisiones y produce el mundo a su imagen y semejanza:

[...] el valor se convierte aquí en el sujeto de un proceso en el cual, cambiando continuamente las formas de dinero y mercancía, modifica su propia magnitud, en cuanto plus valor se desprende de sí mismo como valor originario, se autovaloriza. El movimiento en el cual crea plusvalor es, en efecto, su propio movimiento, y su valorización, por tanto, autovalorización. Ha obtenido la cualidad oculta de agregar valor porque es valor. Pare crías vivientes [...] Como sujeto dominante de tal proceso [...] el valor necesita ante todo de una forma autónoma, en la cual se compruebe su identidad consigo mismo. (MARX, 2001, p. 188)

Marx argumenta cómo dentro del modo de producción se produce un nuevo demiurgo de lo real, que toma decisiones subjetivas sobre la forma de lo real. Esta nueva pseudo subjetividad es el valor que se valoriza a sí mismo, o bien lo que se llama estrictamente capital. Este demiurgo de lo real que permanece oculto, es equiparable con el dios que Benjamin señala y que permanece reprimido. De esta forma los santos dentro del capitalismo, no saben que son santos, no necesariamente saben que rinden culto ininterrumpido al valor que se valoriza, y que en su culto cumplen a cabalidad con los preceptos y normativas del dios oculto. "No lo saben, pero lo hacen." (Ibid., p. 90). 
$* * *$

Denotar la distinción entre una relación de afinidades electivas y una relación de identidad es relevante por las implicaciones políticas que tienen una y otra aproximación. La relación de afinidades electivas de Weber es cómplice de una concepción trágica y progresista de la historia en la medida en la que denota un proceso paulatino, creciente e irreversible de racionalización y secularización. Para Weber, el proceso de racionalización formal e instrumental que se origina en Occidente, tiene un carácter trágico. Se produce una ‘jaula de hierro’ que reproduce las estructuras de poder sacras, pero que se vacía de espíritu y pierde con ello su fundamento ético-religioso. Además, en la medida en la que el proceso de racionalización se presenta como irreversible, la implicación política de ello es que una acción radicalmente transformadora resulta imposible. Ello es mucho más evidente cuando Weber traslada su metáfora de la 'jaula de hierro', al universo de análisis del Estado moderno y el proceso irreversible de la burocratización (WEBER, 1999).

Mientras que la relación de identidad propuesta por Benjamin adelanta, conceptualmente, una crítica a un proceso biopolítico: la incorporación de la estructura de poder en la vida cotidiana. En este caso, la estructura de poder está inserta en la acción misma de los practicantes, lo cual, por un lado, afecta de forma más grave el comportamiento de estos, pero por otro lado también pone en estado de apertura la posibilidad de la acción transformadora. Como se mencionó más arriba, la relación de identidad entre religión y capitalismo, también puede ser descrita como una relación de profanación, en donde los planos sacros y profanos coinciden en un mismo sitio. La acción social no sólo produce y reproduce el culto capitalista, sino que por esa misma razón, es capaz de no producirlo y no reproducirlo. En esa simultaneidad se asoma la posibilidad de los temas mesiánicos de la teoría crítica de Benjamin. El concebir el mundo capitalista de esta forma nos puede ayudar a pensar en formas no ensayadas todavía de lucha en contra de este sistema que nos oprime.

\section{REFERÊNCIAS}

\section{Referências}

Agamben, Giorgio (1998). Homo sacer: El poder soberano y la nuda vida I. Valencia: Pretextos. Agamben, Giorgio (2009). Elogio de la profanación. En AGAMBEN, Profanaciones. Buenos Aires: Adriana Hidalgo.

Althusser, Louis (1969). De El Capital a la filosofía de Marx. En ALTHUSSER y BALIBAR, Para leer El Capital. México: Siglo XXI.

Benjamin, Walter (2005). Tesis sobre el concepto de historia y otros fragmentos. México: Contrahistorias.

Benjamin, Walter (2008). Sobre el concepto de historia. En BENJAMIN, Obras, libro 1, vol. 2. Madrid: Abada.

Benjamin, Walter (2016). "El capitalismo como religion”. Traducción, notas y comentario de Enrique Foffani y Juan Antonio Ennis. Katatay, n 13/14, pp. 178-191, abril de 2016.

Echeverría, Bolívar (2005). "Introducción: Benjamin, la condición judía y la política". En BENJAMIN, Tesis sobre el concepto de historia y otros fragmentos. México: Contrahistorias.

Ennis, Juan y Enrique Foffani, (2016). "Introducción". En BENJAMIN, "El capitalismo como religion”, Traducción, notas y comentario de Enrique Foffani y Juan Antonio Ennis, Katatay, n 13/14, pp. 178-191.

Freud, Sigmund (1979). "El yo y el ello y otras obras". En FREUD, Obras completas, vol. XIX. Buenos Aires: Amorrortu.

Giddens, Anthony (1991). "Introduction". En Max Weber, The Protestant Ethic and the Spirit of Capitalism. London: Harper Collins Academic.

Hamilton, Alastair (2000). "Max Weber's Protestant Ethic and the Spirit of Capitalism". En 
TURNER (ed.), The Cambridge Companion to Weber. Cambridge: Cambridge University Press.

Hegel, G. W. F. (2011). Ciencia de la lógica, Vol. 1. Madrid: UAM-ABADA Editores.

Kalberg, Stephen (1990). "The Rationalization of Action in Max Weber's Sociology of Religion”. Sociological Theory, Vol. 8, No. 1, pp. 58-84, Spring 1990.

102 Löwy, Michael (2006) "Le capitalisme comme religion: Walter Benjamin et Max Weber". Raisons politiques, Presses de Science Po, 2006/3, № 23, 203-220, 2006.

Marx, Karl (2001). El Capital: Crítica de la economía política. Tomo 1, Vols. 1-3. México: Siglo XXI.

Marx, Karl (2005). Crítica de la filosofia del derecho de Hegel. Buenos Aires: Ediciones del signo.

Marx, Karl (2011). "Tesis sobre Feurebach". En ECHEVERRÍA, El materialismo de Marx: Discurso crítico y revolución. México: Ítaca, pp. 116-117.

Marx, Carlos y Federico ENGELS (1955). "Manifiesto del Partido Comunista". En MARX y ENGELS, Obras escogidas en dos tomos, Tomo I. Moscú: Progreso.

Ruano de la Fuente, Yolanda (2001). La libertad como destino. Madrid: Biblioteca Nueva.

Villegas, Francisco (2004). "Introducción del editor". En Max Weber, La ética protestante y el espíritu del capitalismo. México: Fondo de Cultura Económica.

Schluchter, Wolfgang (1985). The Rise of Western Rationalism: Max Weber's Developmental History. California: University of California Press.

Weber, Max (1999). A) "El socialismo". En WEBER, Escritos políticos. España: Altaza.

Weber, Max (1999). B) "Parlamento y gobierno en una Alemania reorganizada". En WEBER, Escritos politicos. España: Altaza.

Weber, Max (2004). La ética protestante y el espíritu del capitalismo. México: Fondo de Cultura Económica.

Weber, Max (2005). Economía y sociedad. 2a ed. México: Fondo de Cultura Económica.

\section{Notas}

1 La particularidad de este ascetismo frente al católico, es la de dedicarse a obrar dentro del mundo, en el quehacer cotidiano, y no recluido en un monasterio. Sin embargo, para Weber, el ascetismo protestante es una continuación y desarrollo del ascetismo monacal de la Edad Media. Sobre este punto véase Weber, 2004, pp. 191-192.

2 Esta idea, no aparece en la primera versión de 1904-1905 de los artículos que conforman $L a$ ética protestante sino hasta su segunda y definitiva versión en 1920.

3 Esto no implica que Weber haya postulado una tesis 'idealista' en cuanto a que 'la causa genética del capitalismo haya sido la ética protestante'. Weber sostiene en otro lugar de su obra que la génesis del capitalismo es previa por varios siglos a la Reforma (WEBER, 2005, pp. 945-1042). Lo único que esta tesis sostiene es que la ética protestante tenía afinidades electivas con el espíritu del capitalismo (SCHLUCHTER, 1985, pp. 142-43; VILLEGAS, 2004, pp. 10-15).

4 Aquí habría que prestar oído a Althusser quien entiende el proceso de producción del conocimiento como uno que tiene que ver con una lectura sintomática. Esa lectura se esmera en reconstruir las ausencias significativas de la lectura. Lo que está en estado de invisibilidad en lo que es visible. (ALTHUSSER, 1969). 